\title{
Mediating Effects Between Objective and Subjective Indicators of Urban Quality of Life: Testing Specific Models for Safety and Access
}

\author{
Timo von Wirth • Adrienne Grêt-Regamey • Michael Stauffacher
}

Accepted: 16 June 2014/Published online: 25 June 2014

(C) Springer Science+Business Media Dordrecht 2014

\begin{abstract}
Enhancing the urban quality of life (QoL) is an explicit policy goal of many countries, yet it is rarely studied using models that relate objective measures of the urban environment to the subjective evaluations of residents. It thus often remains unclear how planning interventions in the urban environment may influence residents' satisfaction with their living conditions. In particular, during periods of significant urban growth, such as those recently observed in Switzerland, which result in diverse, unwanted threats to the local QoL (e.g., loss of green spaces, traffic congestions, and fear of crime). This study uses data from a sample of 1,693 residents that participated in a postal survey about urban QoL. The responses were combined with objective attributes of residential conditions, using geographic information systems. Structural equation models were calibrated to examine the direct and indirect effects of important indicators of urban QoL, namely safety in public spaces and access to central urban facilities. The study sheds further light on the mediating effects between objective characteristics and subjective evaluations that influence the urban QoL. The results showed predominantly low correlations between objective characteristics and subjective evaluations of urban QoL, which confirmed the findings of the few previous studies on this topic. Surprisingly, this study also found a strong link between objective access and perceived accessibility. This relation was explained by the spatial scope of the study region and suggested that the scale discordance theory should be tested in future research. The findings implied that variations in objective measures do not reliably represent differences as evaluated by residents.
\end{abstract}

Keywords Urban quality of life - Structural equation model · Safety · Accessibility · GIS · Switzerland

T. von Wirth $(\bowtie) \cdot$ M. Stauffacher

Institute for Environmental Decisions, Natural and Social Science Interface (NSSI), ETH Zurich, Universitaetstrasse 22, 8092 Zurich, Switzerland

e-mail: timo.vonwirth@env.ethz.ch

A. Grêt-Regamey

Institute for Spatial and Landscape Planning, Planning of Landscape and Urban Systems (PLUS), ETH

Zurich, Stefano-Franscini-Platz 5, 8093 Zurich, Switzerland 


\section{Introduction}

This research article examines the mediating effects between important indicators of urban quality of life (QoL). Currently, examining QoL predominantly concerns life in cities: more than $50 \%$ of the world's population now reside in urban areas (WHO and UN Habitat 2010). Residents' satisfaction with their urban living environment significantly contributes to QoL (Marans and Stimson 2011; Sirgy and Cornwell 2002; Davis and FineDavis 1991; Campbell et al. 1976), in combination with the satisfaction gained in other aspects of life, such as health, relationships, employment and material wealth (Cummins 1996; Sirgy 2012).

Research on urban QoL has encompassed several notions, such as the happy city, neighborhood satisfaction and residential well-being (Ballas 2013; Sirgy et al. 2008). Wellbeing is often expressed as the composite of affective components, such as pleasant emotions and satisfaction with preferences in major life domains (Diener 2006). Hence, a person's well-being is based on subjective experience, whereas QoL usually refers to both the external "objective" circumstances and the person's "subjective" perception and evaluation of these external characteristics, including their bidirectional relations. Consequently, Cummins concluded that "any comprehensive estimate of QoL must comprise both, subjective and objective measures" (2005, p. 700).

Few empirical studies have investigated the interplay of both influences (Liao 2009; McCrea et al. 2006), which predominantly confirmed previous findings of generally weak relationships between objective conditions and subjective QoL in other life domains (Evans and Huxley 2002). However, a recent study by Oswald and Wu (2010) suggests the opposite. This place-specific analysis found a significantly high correlation between measures of objective and subjective human well-being across the US. These contradictory empirical findings indicate the need for additional research, particularly on place-specific QoL.

This study presents an empirical analysis of urban QoL in a rapidly growing region in Switzerland. It combines measures of the objective urban environment with the subjective evaluations of residents in a disaggregated manner. That is, the study applies structural equation models that make parsimonious use of few important predictors of urban QoL; safety in public spaces and access. In doing so, the study seeks to enhance the understanding of the variable interplay in order to contribute to differentiated inferences for urban policy strategies.

\subsection{Current State of Research on Objective and Subjective Indicators of Urban QoL}

There is growing agreement in the scientific literature that objective and subjective measures are necessary in studying the QoL in places. Likewise, policy implications for enhancing QoL (e.g., in a deprived urban neighborhood) should also consider both dimensions (Cummins 2000; Liao 2009). Their related constellation has already been acknowledged in early theories on QoL. In a seminal work on welfare and QoL in (Western) Germany, Zapf (1984) distinguished four combinations between the objective living conditions and their subjective perception by individuals. Zapf combined dichotomous categories for the objective conditions (i.e. good conditions vs. bad conditions) and the individuals' perception (i.e. positive evaluation vs. negative evaluation) resulting in four states. For example, the 'dissatisfaction dilemma' describes a state of dissonance, wherein individuals perceive their living conditions as relatively bad, whereas objective 
measures indicate the opposite. In contrast, individuals reporting positive evaluations of their current state of life, although they adapted to rather poor objective circumstances represent the 'satisfaction paradox'. Thus, people in bad environmental conditions may be satisfied, whereas objectively privileged persons may be dissatisfied (Noll 2002). In fact, Campbell et al. (1976) already pointed to the dilemma, that similar environmental conditions are evaluated differently by individuals. Consequently, informed urban policy making should reflect these distinct QoL states supported by empirical research findings.

The empirical research to date has provided scant, inconsistent findings from studies that tested objective and subjective indicators of urban QoL. On the one hand, there is evidence for low to no correlations between objective and subjective measures of QoL in general, and of urban QoL in particular (Evans and Huxley 2002; McCrea et al. 2006; Liao 2009). The studies emphasized that immediate inferences made from changes in objective conditions (e.g., of the urban living environment) on subjective QoL (e.g., improvements in residents QoL) are not appropriate.

Liao (2009) found only a few significant correlations between objective indicators and subjective perceptions in seven life domains of metropolitan and country areas in Taiwan. The findings of this study indicated that variations in objective QoL across counties do not reliably depict QoL differences, as perceived by the residents, although the results showed consistency in the domain of environmental quality. It is suggested that more detailed studies (e.g., disaggregated to few specific measures) of the relationship could further explicate the interplay of objective and subjective measures (Liao 2009).

McCrea et al. (2006) presented an empirical analysis of urban QoL in an Australian study region. The study jointly used objective and subjective indicators in a structural equation model and confirmed the hypothesized relationships. Weak relationships (i.e. low magnitude of coefficients) were found between measures of objective access and subjectively perceived access and between objective density, cost of housing and a broad measure of perceived overcrowding. The objective measures explained little variance in perceived access and overcrowding. The study identified limitations in omitting important predictors known to influence urban QoL, such as crime and safety. In addition, McCrea et al. used a broad measure for perceived overcrowding in a large-scale study region in Australia. However, the patterns of relations between objective and subjective factors may significantly differ in a more densely populated, smaller scale setting in Western Europe.

A recent study by Oswald and $\mathrm{Wu}$ (2010) yielded contrasting results. It found that the relation between subjective assessments and objective measures of QoL was indeed meaningful. The study used a subjective life satisfaction measure to show the same "pattern of QoL as previously estimated from solely non-subjective data" (p. 576). This place-specific study found a significant high correlation $(r=0.6)$ between objective and subjective human well-being across the US, based on place amenity effects. Oswald and $\mathrm{Wu}$ concluded that subjective measures of QoL offer "genuine information about the quality of human lives" (p. 579).

A study by Angur et al. (2004) also found congruence between objective and subjective predictors of residents' QoL in their neighborhood. The objective measures (e.g., percentage of vacant homes in the neighborhood) were significantly related to residents' satisfaction with their homes in general and with the perceived security against crime. The findings showed a statistically significant degree of correlation, however, the objective variables were less strongly associated with overall neighborhood quality than were the subjective variables.

Because of the partly conflicting findings of previous studies, the question of the relation between objective and subjective factors remains unresolved. They imply the need 
for additional research-particularly in place-specific QoL-that focuses on specific domains instead of broad, hence unspecific, categories. Thus, the present study examines their relations as predictors of urban QoL by using the particular factors of safety in public spaces and accessibility to services and facilities.

These dimensions were selected according to the optimal centrality theory (Archibugi 2001; Cicerchia 1999) and the theory of city size (Bettencourt et al. 2007; Batty 2013). The optimal centrality theory describes the relation between the beneficial effects of urban centrality (e.g., easy access to services, facilities, opportunities) and the unwanted, negative aspects of central urban locations (e.g., overcrowding, safety issues, social exclusion by higher land prices). The theory postulates that the trade-off between the benefits of "city effect" and the costs of "urban load" can be maximized, which would then describe a preferable state of urban size and result in a maximum of net benefits to urban QoL. Similarly, in their theory of city size, Bettencourt et al. (2007) identified both the benefits and unwanted consequences of urban scale, such as increasing crime rates with increasing city size. Thus, in the present study, accessibility is a measure of the benefits of urban growth, and (threats to) safety in public spaces is a variable representing unwanted cost effects.

Safety in public space (also referred to as security) was found to be an important predictor of urban QoL (Sirgy 2012). There is evidence that lack of safety is adversely correlated with the QoL of residents (Michalos and Zumbo 2000). However, the way safety in public space is measured often varies across studies. Many studies of public safety have not accounted for different sources of threats, such as crime, traffic accidents, unattended dogs and poor roadway infrastructure (Loukaitou-Sideris 2006). Safety in public urban spaces is particularly related to the threats perceived by pedestrians and cyclists. Hence, Loukaitou-Sideris found two main sources of perceived threats in crime and traffic accidents (i.e., pedestrian/cyclist—automobile crashes). The only study that examined the relationships between objective crime data and subjective feelings of safety was carried out by Lee and Marans (1980) in the metropolitan area of Detroit. However, they used safety as factor in order to understand scale discordance as one explanation for weak relationships between objective and subjective measures. Moreover, other scholars measured safety in public spaces either objectively, such as by the rates of reported crimes in a neighborhood (Loukaitou-Sideris et al. 2001; Giles-Corti and Donovan 2002) or by subjective perception (Kitchen and Williams 2010; Michalos and Zumbo 2000).

While the lack of safety in public spaces is considered associated with urban dissatisfaction and stress, the accessibility to important services and facilities in the urban realm (e.g., access to public transportation, shops, gastronomy, schools) was found to be a key amenity, contributing significantly to residents' satisfaction with their urban environment (Talen 2002; Sirgy and Cornwell 2002; Rogerson et al. 1989). Although it is a complex concept, many studies have measured accessibility using either the objective distance or the perceived proximity to such services and facilities. Recently, Zenker et al. (2013) confirmed that "access to central services in cities" was the strongest predictor of satisfaction in a sample of German agglomerations. However, their approach to an index of city satisfaction was built only on the perceived, self-reported ratings of residents and did not integrate them with objective measures. McCrea et al. (2006) found a significant but weak relationship between objective access and the accessibility ratings perceived by residents in the Australian study region.

Despite the previous research, statistical models that include objective measures and perceived attributes for safety in public spaces and access do not yet exist. Consequently, McCrea et al. emphasized the importance "to continue to develop research designs that 
explicitly seek to investigate the links between the objective measures and the subjective evaluations of the urban environment" (2011a, p. 85).

\subsection{Rationales and Hypotheses for this Study}

This study analyses the mediating effects of specific objective and subjective indicators of urban QoL. An effect of mediation occurs when a factor (i.e., in this study, the subjective evaluation) accounts for the relation between an explanatory variable (i.e., the objective urban conditions) and a criterion variable (i.e., urban QoL). Mediation analysis helps to clarify "how or why such effects occur" (Baron and Kenny 1986, p. 1176). Mediating factors can influence urban QoL on different geographical scales. For example, the geographical scale of reference might be the local neighborhood, the city, or the regional scale. However, satisfaction with the urban environment in these different spatial domains were found to be correlated (Sirgy and Cornwell 2002; Lu 1999; Campbell et al. 1976). Because of this interrelatedness, urban QoL might also be seen as a composite of neighborhood, city and regional satisfaction (McCrea et al. 2011b), which, consequently, is utilized in this study.

In modeling urban QoL by using both objective characteristics of the environment and subjective measures of individuals, two different entities of study have to be combined. That is, the objective conditions refer to the characteristics of places, while the subjective survey ratings refer to individuals. Measurements of the former are often based on spatial units of reference (e.g., a neighborhood or city zone), whereas the latter refers to a household in which the individual lives. Each survey participant can be identified by a distinct place locator based on the households' address. Geocoding by geographic information systems (GIS) makes this possible. When the household location of a survey participant is defined, other spatial information can be linked to that location, such as the distance to important urban facilities (e.g., station, shops, and school). The individual's location can also be related to other geocoded information, such as the population census and building register. Hence, the use of GIS permits the integration of survey data with objective spatial information (Marans and Stimson 2011).

This study tests the relational paths between safety in public space and access to predict urban QoL. In this analysis, seven structural relations are hypothesized in order to gain better understanding of how access to services, as a measure of urban centrality, and safety in public space are mediated by subjective perception in their influence on urban QoL (see Fig. 2, which illustrates the structural and measurement models and displays the hypotheses given below in the form of arrows). The path model not only estimates the intensity of relationships between the objective and subjective measures but also tests the effects of mediation by the subjective measures of access and safety. Hence, the following hypotheses are proposed (Table 1).

\section{Methods}

\subsection{The Study Area}

The analysis was carried out in the Limmattal area, a suburban settlement belt in the agglomeration of Zurich, Switzerland. Extending over $24 \mathrm{~km}$ along the Limmat River, it is one of the major growth corridors in the expansion of the largest city in Switzerland. The particular study region consists of two municipalities, Schlieren and Dietikon, as shown in 
Table 1 Hypotheses for this study

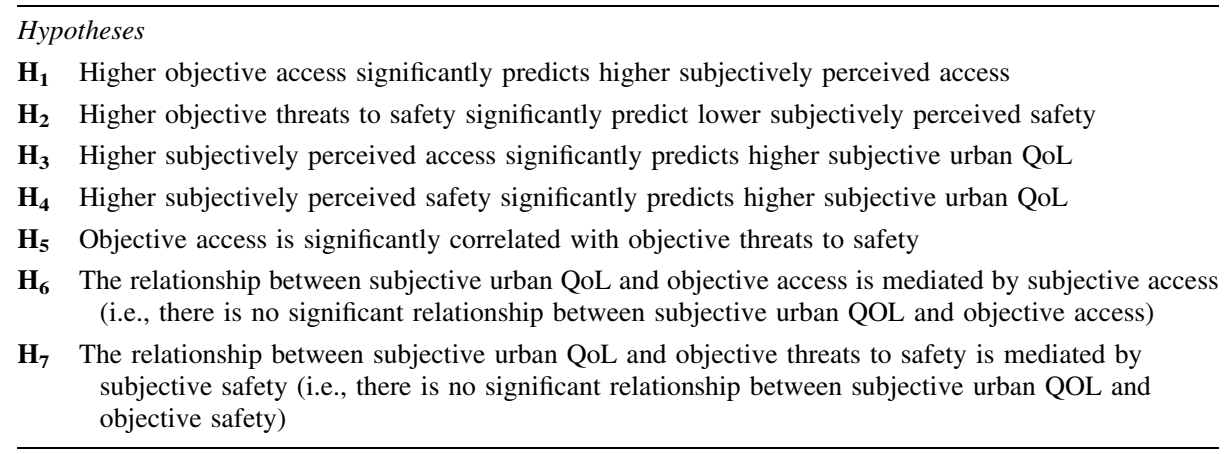

Fig. 1. Combined, these municipalities comprise an area of 1,582 ha including 41,942 inhabitants and 31,365 employees as of 2012 (Statistical Office Canton Zurich 2013).

The study area was selected as a typical suburban region that is described as "a miniature of Switzerland" (Schumacher et al. 2004, p. 232) characterized by a patchwork of land uses in a polycentric suburban form. The municipalities are growing rapidly in terms of population and workplaces. Between 2007 and 2012, the population increased by 5,692 or $15.7 \%$, compared to the average increase in Switzerland of $5.9 \%$ during this period. Current forecasts expect the population to increase by 7,000 inhabitants (17\%) until the year 2025 (ZPL 2012). The regional economy is dominated by service industries (e.g., the media, logistics and health care sectors) and a few remaining manufacturing sites. The number of jobs is also projected to increase significantly from 31,365 (2011) to 37,000 (18\%) until 2025 (ZPL 2012).

With lower (but rising) land prices and rental rates for housing and office space, compared to the central areas of Zurich, the region currently is attracting migration. The share of non-Swiss citizens is $42.7 \%$ (in 2012) compared to the average of $23.3 \%$ in Switzerland (BfS 2013). The study region also provides important spatial, economic, and social, as well as recreational and ecological capacities for the core city of Zurich. Regional growth currently results in pertinent land consumption and intense urbanization. Former industrial sites are now being transformed into new, large-scale housing areas. The rising demand for mobility, which has resulted in increased commuting and leisure traffic, has led to unwanted effects (e.g., noise emissions and traffic congestions). In response, urban planning in the region currently aims at compact city development with further densification in central zones. The current urbanization has been accompanied by debates about safety in public spaces, which have been publicized in the local media (e.g., on crime incidents). However, the causes underlying the interplay of objective safety and the subjective feeling of safety remain unclear.

In short, the rapid growth in the study region poses considerable challenges in the diverse aspects of the local and regional QoL.

\subsection{Sampling Procedure}

Data were obtained through a survey on urban QoL conducted between May and July 2013. A representative sample of residents aged 18 years and older living in the study area was randomly selected from the citizen register by applying a stratified random sampling 


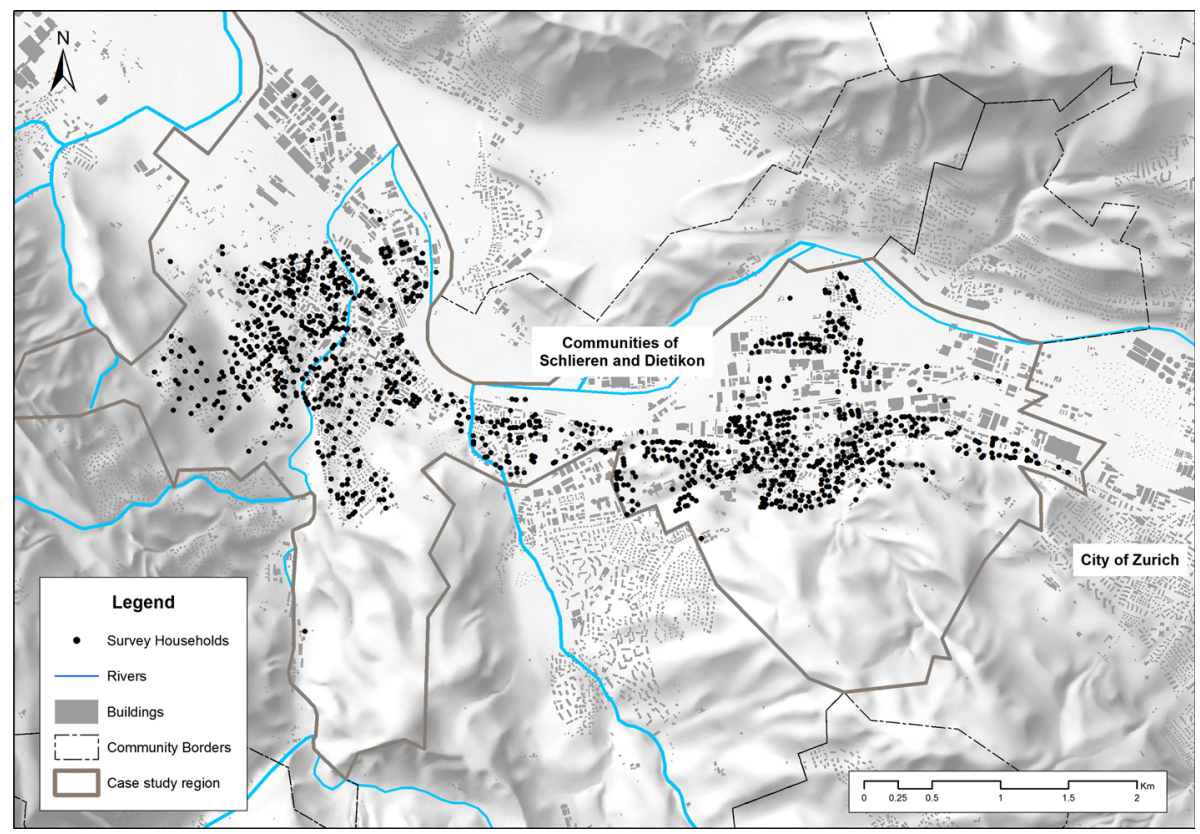

Fig. 1 Map of the Limmattal region in Switzerland. Spatial dispersion of survey respondents' household locations. Source: Swisstopo 2010

for the equal representation of women and men. The questionnaire was distributed to 5,500 residents of which 1,699 completed and returned them. The response rate was thus $31 \%$, and the response sample was representative of the population in the study region.

The socio-demographic, household and housing characteristics of the sample suitably fit the population census data as of 2011/2012 (see Table 2). However, respondents had a higher median age, showed higher levels of education and were more likely to be Swiss citizens. The sample is also spatially representative of local subunits, such as administrative city districts.

\subsection{Selection of Measures}

In order to determine the urban QoL attributes that are currently relevant for the population in the study region, we first conducted a thorough literature review on urban QoL predictors. Second, two focus group workshops were carried out with local city planning experts $(\mathrm{N}=5)$ and with residents $(\mathrm{N}=7)$ from the study region. The workshops aimed at identifying the relevant factors that influence the urban QoL in the local and regional context. Applying the personas technique (Grudin and Pruitt 2002), the first workshop focused primarily on the objective characteristics of quality in the urban environment. The participating experts collected and discussed concrete attributes that contribute to a high level of urban QoL and determined which factors have limiting effects on the QoL. The resulting set of attributes contained the following dimensions: safety, density of utilization, accessibility and connectedness of functions, amenity values of public spaces, compactness, and clarity of urban design. 
Table 2 Sample description and comparison with population characteristics

\begin{tabular}{lll}
\hline Variable (unit) & Survey sample 2013 & Census $^{\mathrm{a}}$ \\
\hline Percentage female of those aged 18 and over & 51.4 & 49.2 \\
Median age of those aged 18 and over (Years) & 49 & 43 \\
Percentage born in Switzerland & 57.5 & 57.2 \\
Percentage with Swiss nationality & 69.5 & 7.9 \\
Percentage with a Master degree or post-graduate qualification & 10.2 & 14.7 \\
Percentage with mandatory high school degree as qualification & 19.5 & 2.3 \\
Average household size (Persons) & 2.5 & 21.8 \\
Percentage of car free households & 20.8 & 78 \\
Median of net dwelling area (in m ${ }^{2}$ ) & 93 & 7.6 \\
Percentage of dwellings that are single detached houses & 10.2 & 71.7 \\
Percentage of dwellings that are multiple apartment houses & 79.3 & 74.1 \\
Percentage of households renting (vs. owning) of those aged 18 and over & 72.4 & \\
\hline
\end{tabular}

${ }^{a}$ Census Data from the following sources: BfS (2013); Statistical Office Canton Zurich (2013)

During the second workshop, key determinants of residential well-being were explored based on a stepwise procedure. Participating residents were asked first to describe their residential needs with respect to urban QoL; second, the concrete attributes that contribute to their satisfaction with the current urban environment were identified; third, participants noted future attributes that might contribute to their residential well-being. In addition, residents ranked the attributes according to their importance. The resulting set of attributes describing residential well-being included the following: safety in public spaces, quietness/ absence of noise, places for and quality of interaction (e.g., with neighbors), places and sense of belonging, proximity to services and functions for necessities, and accessibility to green spaces and recreation areas.

The attributes identified in both explorative workshops were operationalized in the paper-and-pencil questionnaire. Further dimensions that were found to be important predictor variables in the literature review on urban QoL were added (e.g., building aesthetics and affordability of housing).

\subsection{Measured Variables}

The paper-and-pencil questionnaire collected the subjective assessments of survey respondents on diverse aspects of urban QoL. It covered urban QoL with satisfaction measures on four spatial scales and satisfaction with seven life domains (not reported here). Measurement scales also included a six-item place attachment scale, residential and household variables as well as socio-economic variables. All variables used for this study are shown in Table 4 in the "Appendix".

\subsubsection{Subjective Variables}

The latent variable urban quality of life was measured using three manifest variables. First, the item regional satisfaction was based on the question: "In general, how satisfied are you with the region you are living in?" Residents answered according to a ten-point scale from 
$1=$ very dissatisfied to $10=$ very satisfied. Second, the item satisfaction with city asked residents how satisfied they were with "the city you are living in." Answers were also measured on a ten-point scale from $1=$ very dissatisfied to $10=$ very satisfied. Third, the item neighborhood satisfaction was based on responses to the question "In general, how satisfied are you with your neighborhood?" which were also measured on the tenpoint scale from $1=$ very dissatisfied to $10=$ very satisfied. The ten-point scale was chosen to guarantee the coherence of the measurement scales with the Statistics on Income and Living Conditions (SILC) instrument. SILC is an established instrument used in European policy analysis. Because it assesses cross-sectional and longitudinal data on QoL conditions in all European Union member states, including Switzerland (since 2003), it could be a valuable reference for national and international comparisons in future analyses.

The manifest variables used to measure subjectively perceived safety and access were formulated in questions asking the participants how much they agreed or disagreed with individual item statements. The responses to each item were scored on a five-point scale (from $1=$ do not agree at all to $5=\mathrm{I}$ fully agree.). Safety in public spaces was measured using three items referring to crime, road safety and the general sense of safety at night: "There are only few crime incidents here"; "I feel safe cycling here in the streets" and "Streets and public places are safe here at night". Finally, subjective judgments about access to services and facilities (i.e., public transport, shopping, school/ kindergarten, and gastronomy) was measured based on four items: "I live close to the train station"; "Shopping facilities are nearby here"; "I can reach a kindergarten or school quickly by walking"; and "A restaurant or a Café is accessible within a short distance from here". In the study region, all school locations, primary and secondary, also host a kindergarten at the same location; therefore, both could be referred to in one item.

In measuring the perceptions of residents in cities, it is often difficult to define the spatial boundaries of the unit of reference (e.g., the neighborhood). However, previous research showed evidence of a significant dissimilarity between resident- and census-defined spatial unities. For example, individual perceptions of neighborhood boundaries can differ markedly (Coulton et al. 2001). Thus, the wording of items in the survey referred to the neighborhood in general, and no spatial boundaries were defined for the spatial unit of reference.

\subsubsection{Objective Variables}

Objective access was operationalized by three manifest distance measures. The ArcGIS 10.1 spatial analyst cost distance function was used to calculate the distances of each household. Cost-weighted distance analysis was applied because, in contrast to the straight line (Euclidean) distance, it delivers representative distance values, particularly in regions where geographical factors demand routes longer than a straight line between two points (e.g., railroad tracks, rivers, and mountains), which is particularly the case in the study region. It is referred to as the "effective distance" in modifying the straight line distance for the effects of landscape and moving behavior (Adriaensen et al. 2003). In costweighted distance, the distance is a cost factor. This procedure uses raster cells (here: $1 \mathrm{~m} \times 1 \mathrm{~m}$ ) and takes into account the cell's distance and the cost of moving through it. The cost for moving through a cell is defined by resistance values, which enables specifying route preferences (e.g., by assigning high resistance values for geographic obstacles). Movable cells were assigned with a resistance value of 1 . Roads with more than two lanes were given a value of 3 , and larger tunnels were assigned a value of 5 , whereas the 
destination cell itself has the lowest costs, and accordingly is set to 0 . The resistance value for non-traversable spatial obstacles, such as train tracks and rivers, were set to an extreme resistance value of 10,000 to force the least-cost algorithm to select realistic bypasses (e.g., passing over the closest bridge).

The outcome was the least cost or the shortest path from a chosen destination to the survey household. The unit of distance measurement was a cost value that can be converted into a distance measure by multiplying the cost by the cell size (Adriaensen et al. 2003). Distances were calculated between several functional destinations and each survey household within the study region (e.g., nearest train station and school/kindergarten).

The latent variable objective safety was measured using two manifest objective variables, accident density and crime density. While accident density captured all traffic accidents in public space, crime density accounted for the registered crime incidents (vandalism and theft) in public spaces. Both data sets were provided by the Cantonal Police for the Canton of Zurich for the latest available year (2012) and include all police records that were given a spatial coordinate for the incident location. Incident locations were mapped on the hectare raster grid $(100 \mathrm{~m} \times 100 \mathrm{~m}$; the smallest spatial unit for which information is provided by the Swiss Federal office of Statistics), and density measures for accidents per hectare raster cell and crime incidents per hectare raster were calculated. Accordingly, the density values for each survey respondent were based on the respective accident and crime values of the hectare cell in which the household was located.

\subsubsection{Linking Subjective and Objective Attributes by Spatial Location}

The information gained from the survey respondents was linked to information describing the current urban realm in the study region. This observable information on the urban environment had a clear geographical reference, which means that every object's spatial location (e.g., of a school building within the city) could be described by distinct geometric coordinates. Similarly, the survey data received geometric information according to the spatial household location of each survey respondent. This process, which is known as geocoding, added geodetic coordinates to every subject of the QoL database (i.e., each survey respondent) and used the address information available from the citizen register (street, house number, and postal code). Geocoding was carried out based on the digital street network data for Switzerland provided by the Swiss Post Service, combined with digital building information administered by the Swiss Federal office of Statistics. Combining both datasets guaranteed a high accuracy of geometric reference data for street and building positions. Of the 1,699 responding resident households, geocoding could be carried out for 1,693 addresses. Six subjects are missing because of incomplete address information. Accordingly, these subjects were excluded from the further analysis. This is because the objective data for the urban environment of each household needed to be calculated based on the household locations of the survey respondents. The final dataset for the modeling thus contains 1,693 subjects. The spatial distribution of the sample is displayed in Fig. 1. ArcGIS 10.1 was used for the spatial analysis of the objective characteristics of the respondents' locations (e.g., calculation of distances from household location to important urban facilities; matching each household with information from the geocoded census and police information, such as population densities, density of crime and accidents). 


\subsection{Data Analysis}

\subsubsection{Data Quality and Transformation}

The data analysis of the manifest variables showed no or few missing values. The objective manifest variables had none. All subjective QoL measures had $1 \%$ or less missing values; all subjective variables (for access and safety) had between 1.4 and $4.6 \%$ missing values. The pattern of these incomplete data was identified as missing completely at random (Little's MCAR test = non-significant). However, two manifest variables had a higher number of missing values [perceived access to school/kindergarten at $8.2 \%$; perceived safety ("cycling here in the streets") at $7.6 \%$ ]. The missing pattern in both was identified as missing at random, which means that the probability of missing data in the particular variable depended on other observed variables, but not on the missing data itself. This was the case for the variable, access to school/kindergarten, which may be related to the type of household (e.g., if the household is without children). In addition, the variable perceived safety ("cycling here in the streets") did not apply to all residents and was presumably left out by residents who did not use bicycles. This question asked for the cyclist's perception of safety on the city roads.

Traditional approaches to handling incomplete data include case deletion or single imputation (e.g., when missing values are replaced by the mean of the observed values for that item). While the first would have biased the sample towards residents with children in school/kindergarten and those using bicycles, the latter could distort data distributions and variable relations. With mean substitution, variance would have been strongly attenuated which, then could have produced biased covariances with other dimensions. Consequently, the multiple imputation (MI) technique was applied. MI proofed to have significant advances over traditional approaches (Acock 2005; Schafer and Graham 2002). Each missing value was replaced by a pooled estimate of multiple value simulations. The repeated estimation of each value was based on a Markov Chain Monte Carlo algorithm. It ensured that the uncertainty of missing values was captured by adding the error variance between the simulation steps. Hence, an imputed dataset with unbiased standard errors was gained.

All manifest subjective variables used in the analysis were only slightly skewed, with absolute statistics for skewness and kurtosis below \pm 1 (e.g., negative skewness ranging from -0.009 to -0.963 and positive from 0.011 to 0.777 ). Because of the large sample size, the visual inspection of univariate QQ- plots was chosen for further analysis and confirmed acceptable close-to-normal distributions for all manifest subjective variables. The objective measures for access were only slightly skewed, however; distance to school/ kindergarten had a positive skewness of 1.78. Distance values were not transformed because the additional inspection of histograms still showed a close-to-normal distribution. In addition, not transforming distance measures permitted the direct interpretation of the access values. This also applied to the values for objective safety. Crime and traffic densities were positively skewed $(3.41 ; 3.71)$. Histogram inspection showed reasonably normal distributions, and tests with square root and natural log transformations did not result in considerable improvements. Hence, data transformation was not applied.

\subsubsection{Analytic Procedure}

To test the proposed hypotheses, structural equation modeling (SEM) was chosen to analyze the effect of objective and subjective variables on urban QoL. SEM is suitable here 
because it can incorporate both directly observed (i.e., manifest) and not directly observable (i.e., latent) variables while analyzing data for inferential purposes (e.g., for their mediating effects). Hence, SEM helps to explain how well a theoretical model that is a priori hypothesized serves as an approximation of the mechanisms underlying the observed associations. In contrast to traditional multivariate procedures, SEM is capable of assessing and accounting for measurement error deriving from the observed variables. Unbiased estimates are calculated for the relationships between latent constructs in the main structural model. Indeed, providing explicit estimates of the error parameters is particularly necessary in social and behavioral research when the measurement of variables is often recognized as difficult and error-prone (e.g., for the concept of urban QoL). Within the framework of structural equation modeling, maximum likelihood estimation was used in the measurement and structural models, based on the correlation matrix in AMOS 20.0 (Arbuckle 2011). Figure 2 illustrates the conceptual model, which entails five measurement models based on 15 manifest variables and the structural model. The model uses 10 perceived manifest variables that were measured by the survey to explain three latent variables. It then further uses five objective manifest variables to measure two latent objective variables.

In the visual representation of the path model, the rectangles represent observed manifest variables and the ellipses represent latent variables. A one-way arrow displays an unidirectional relationship, whereas the two-way arrow stands for hypothesized covariance. To ensure clarity in Fig. 2, the symbols for measurement error components and residual terms are not displayed.

\section{Results}

The average score for the urban QoL was 7.21 ( $\mathrm{SD}=1.81$; range 1-10). The descriptive results of all manifest variables are provided in Table 4 in the "Appendix", including the correlational matrix. Based on the correlational data, three models were estimated. Model 1 tested a mediated path model in which the relationships between the two objective latent variables and urban QOL were mediated by the perceived latent measures for access and safety. In model 2, the direct paths between the objective latent variables for access and safety and the latent factor urban QOL were added in order to test these paths for significance, which means that the subjective latent variables for access and safety would fully mediate these paths. The goodness of fit statistics were evaluated. Finally, in model 3 additional paths that significantly contributed to an improvement of the model fit were added, following the screening of modification indices and standardized residuals carried out in model 2.

\subsection{Structural Equation Modeling}

Structural equation models were estimated to predict urban QoL and examine the mediating effects between objective and subjective measures. In model 1, the five measurement models were found eligible; all manifest variables loaded well onto their respective latent variables. The standardized factor coefficients for the measurement models are shown in Fig. 2; the lowest standardized factor coefficient was 0.41 .

The goodness of fit statistics indicated a fair fit to the data for model 1 . The Chi square statistics were, not surprisingly, rather poor, which can be explained partly by the sensitivity of Chi square statistics to sample size (Byrne 2010). However, the RMSEA (0.053) 


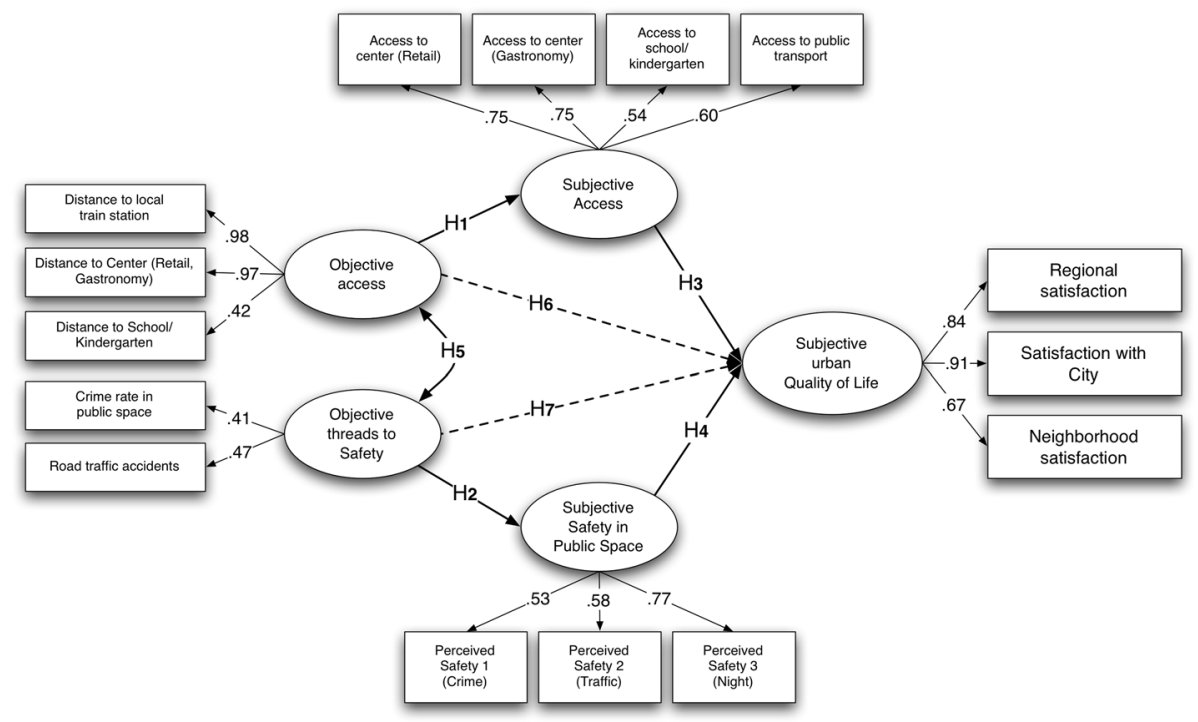

Fig. 2 Structural equation model with manifest variables, latent variables and hypothesized structural paths (straight arrow lines indicating hypothesized as significant path; and dashed arrow lines indicating path hypothesized as non-significant). Factor loadings are displayed for the five measurement models (see the text for more details)

and SRMR (0.057) showed an acceptable good fit in considering the thresholds for the absolute fit indices according to Steiger (2007). RMSEA values $<0.07$, and following $\mathrm{Hu}$ and Bentler (1999), a SRMR value $<0.08$ describe acceptable model fits. Table 3 displays the estimates and goodness of fit indices for all three models.

Test of hypotheses in SEM found a significant association between objectively measured access and subjectively perceived access. With a standardized regression coefficient of -0.61 , objective access accounted for $37 \%$ of the variance explained in subjectively perceived access. Thus, hypothesis 1 is supported. The negative regression estimate means that subjectively perceived access increases according to shorter objective distances.

The test of hypothesis 2 found objective threats to safety was a significant predictor of subjective safety (standardized $\beta=-0.24$ ). The higher the crime density and the density of traffic accidents, the lower the perception of safety in public spaces, although only $6 \%$ of the variation in perceived safety was explained. Subjectively perceived access and subjective safety in public spaces were both found to be significant predictors of urban QoL. Thus, both $\mathrm{H}_{3}$ and $\mathrm{H}_{4}$ are supported. The two latent variables combined explain $24 \%$ of the variation in urban QoL. Hypothesis 5 is also supported because the two objective variables, access and safety, are significantly correlated $(r=0.44)$. The more central one's location in the city (i.e., the smaller the distances to central services), the higher the objective rate of crime and traffic accidents in public space.

The effects of mediation through subjectively perceived access and perceived safety were tested by adding the two direct paths between the objective latent variables for access and safety on one hand and QoL on the other hand, which is presented in model 2. Adding the paths slightly improved the model fit $\left[\chi^{2}(6)=23.7 ; p<0.001\right]$, as indicated by the 
Table 3 Resulting estimates of the structural equation model with goodness of fit statistics $(\mathrm{N}=1,693)$

\begin{tabular}{|c|c|c|c|c|c|c|c|c|c|}
\hline \multirow[t]{2}{*}{ Structural model } & \multicolumn{3}{|c|}{ Model 1} & \multicolumn{3}{|c|}{ Model 2} & \multicolumn{3}{|c|}{ Model 3} \\
\hline & Est. & Sig. & $R^{2}$ & Est. & Sig. & $R^{2}$ & Est. & Sig. & $R^{2}$ \\
\hline \multicolumn{10}{|l|}{ Variables } \\
\hline$\rightarrow$ Subjective access & & & 0.37 & & & 0.38 & & & 0.37 \\
\hline Objective access $\left(\mathrm{H}_{1}\right)$ & -0.61 & $* * *$ & & -0.62 & $* * *$ & & -0.61 & $* * *$ & \\
\hline$\rightarrow$ Subjective urban safety & & & 0.06 & & & 0.05 & & & 0.05 \\
\hline Objective threats to Safety $\left(\mathrm{H}_{2}\right)$ & -0.24 & $* * *$ & & -0.23 & $* * *$ & & -0.23 & $* * *$ & \\
\hline$\rightarrow$ Subjective urban QoL & & & 0.24 & & & 0.24 & & & 0.25 \\
\hline Subjective access $\left(\mathrm{H}_{3}\right)$ & 0.22 & $* * *$ & & 0.29 & $* * *$ & & 0.28 & $* * *$ & \\
\hline $\begin{array}{l}\text { Subjective safety }\left(\mathrm{H}_{4}\right) \\
\leftrightarrow \text { Objective access }\end{array}$ & 0.46 & $* * *$ & & 0.45 & $* * *$ & & 0.45 & $* * *$ & \\
\hline $\begin{array}{l}\text { Objective threats to Safety }\left(\mathrm{H}_{5}\right) \\
\rightarrow \text { Subjective urban } \mathrm{QoL}\end{array}$ & -0.44 & $* * *$ & & -0.43 & $* * *$ & & -0.43 & $* * *$ & \\
\hline Objective access $\left(\mathrm{H}_{6}\right)$ & & & & 0.13 & $*$ & & 0.12 & $*$ & \\
\hline Objective threats to safety $\left(\mathrm{H}_{7}\right)$ & & & & 0.06 & n.s. & & 0.06 & n.s. & \\
\hline Goodness of fit indices & $\begin{array}{l}\chi^{2}(258 \\
p<0.0 \\
\text { Normec } \\
\text { SRMR } \\
\text { RMSE } \\
\text { AIC }= \\
\text { GFI }= \\
\text { CFI }=\end{array}$ & $\begin{array}{l}=2,745 \\
1 \\
\chi^{2}=10 \\
=0.057 \\
=0.053 \\
.949 .55 \\
.906 \\
.891\end{array}$ & $\begin{array}{l}5.6 \\
3.6 \\
3\end{array}$ & $\begin{array}{l}\chi^{2}(252 \\
p<0.0 \\
\text { Normec } \\
\text { SRMR } \\
\text { RMSE } \\
\text { AIC }= \\
\text { GFI }= \\
\text { CFI }=\end{array}$ & $\begin{array}{l}=2,7 \\
1 \\
\chi^{2}=1 \\
=0.05 \\
=0.0 \\
2,937.9 \\
.906 \\
.892\end{array}$ & $\begin{array}{l}1.9 \\
0.8 \\
4 \\
3\end{array}$ & $\begin{array}{l}\chi^{2}(231 \\
p<0.0 \\
\text { Normec } \\
\text { SRMR } \\
\text { RMSE } \\
\text { AIC }= \\
\text { GFI }= \\
\text { CFI }=\end{array}$ & $\begin{array}{l}=1,1 \\
1 \\
\chi^{2}= \\
=0.045 \\
=0.0 \\
, 366.9 \\
.958 \\
961\end{array}$ & \\
\hline
\end{tabular}

Path to $(\rightarrow)$; path from (in italics); correlation $(\leftrightarrow)$

$* p<0.05$; ** $p<0.01$; *** $p<0.001$

test result showing a significant $\chi^{2}$ difference. The goodness of fit indices remain the same. With regard to hypothesis 6, objective access was weakly associated directly with QoL, which showed that this path was only partially mediated by subjective access (rejecting $\mathrm{H}_{6}$ ). The correlation between objective threats to safety and QoL (hypothesis 7) is nonsignificant, which supports the assumption that this path is fully mediated by subjective perception of safety.

Table 3 shows that compared to model 2, in model 3, additional paths could be added, which significantly improved the fit of the model. No new associations were added to the structural model. However, seven new paths were implemented in the measurement models. The fit indices now indicated an overall good fit. Correlated error terms were found between manifest variables in the measurement model of subjective urban access: perceived access to school/kindergarten and perceived access to public transport as well as perceived access to public transport with access to central shopping facilities. In addition, the error term of the manifest variables for objective access showed a significantly shared variance with manifest perceived access variables: objective distance to school with perceived access to school and objective distance to station with perceived access to public transport. Adding these error correlations only slightly affected the model estimates, 
whereas the model fit to the data was improved significantly $\left[\chi^{2} \quad(21)=1,612.9\right.$; $p<0.001]$.

\section{Discussion}

This study examined mediating effects between specific objective measures of the urban environment and residents' perceived QoL by using structural equation models. The study found significant relationships of varying strengths between the objectively and subjectively measured variables.

\subsection{Interpretation and Contextualization of the Findings}

A significant association between objective access and subjective access was identified. Surprisingly, this association was found to be relatively strong, which means that the subjective evaluation of local access significantly corresponded with the objective conditions. Improvements in the residents' access to services and facilities (e.g., by opening new local stores in the neighborhood and shortening travel times with new public transport infrastructure) would be reflected in the subjective evaluations and would positively affect the urban QoL of residents. This implies that measures of perceived accessibility would be a meaningful representation of the objective circumstances to a certain degree. This finding is in contrast to McCrea et al. (2006), who found only weak links between the latent measures of objective and subjective access. The spatial scope and typology of the study region may have played a significant role here. Whilst the Swiss region used in this study is relatively compact, McCrea and colleagues used data for the Australian region of South East Queensland, where distances from survey respondents' households to central locations are much greater. In addition, the Swiss study focused on a suburban settlement area, whereas the large-scale study region in McCrea et al. comprised diverging settlement patterns from inner-city districts to remote rural locations. Both the spatial extent and the relative homogeneity of settlement patterns may affect the congruency of objective measures and their subjective evaluation.

This interpretation can be supported by the scale discordance concept of Lee and Marans (1980) which showed that the discrepancy between objective spatial units of measurement and the individual's perception of these spatial units (e.g., a city district) significantly affected the correlation of these measures. Thus, in studies of smaller territories, the effect of scale discordance may be weaker. In fact, Angur noted that "congruence among objective and subjective indicators was stronger when the neighborhoods in question were small" (2004, p. 51). Consequently, it is postulated that the smaller the spatial scope of the study region, the greater the likelihood of congruency in the relationship of objective and subjective indicators of urban access. Thus, for planning purposes, small-scale studies are probably more informative.

We found a significant but weak influence of measured objective safety in public space on the subjective evaluations of safety. This finding aligns with Lee and Marans (1980) who found modest correlations between the objective measures of crime and the survey respondents' feelings of safety. This would imply that interventions into street safety and reduction of crime could have an improving effect on people's personal feeling of safety. Incidents that pose a threat to objective safety, such as crime and traffic accidents, are significant stress factors because the objective safety impacts negatively on perceived safety, which in turn significantly affects urban QoL. 
Perceived access and perceived safety were found to be significant predictors of urban QoL. Perceived safety was identified as the stronger predictor of the two when the standardized beta coefficients were considered. This finding suggests that safety in public spaces has a greater influence than does the proximity to central services. According to optimal centrality theory (Cicerchia 1999; Archibugi 2001) this indicates the importance of feeling safe in an urban environment over the perceived high centrality. The importance of safety is interpreted as one of residents' motive in choosing suburban locations over core city centers (in addition to other factors, e.g., housing costs and availability of space), which is an ongoing trend in the Swiss agglomerations. In suburban settlement areas, people still have comparably good access to local suburban centers, while they expect stressful factors, such as threats to safety being fewer or absent. However, the current population growth in Swiss agglomerations also leads to rapid densification in these suburban settlements. According to optimal centrality theory, certain levels of suburban growth might be reached, wherein the negative effects of urban load result in a perceived loss in urban QoL.

The hypothesized effects of mediation were only partly confirmed in this study. The effect of objective access was only partially mediated by subjective access. This finding aligns with McCrea et al. (2006) and suggests that additional variables may be associated with objective access, which could positively affect urban QoL. In contrast, the influence of objective safety on urban QoL was fully mediated by the subjective evaluation of safety.

\subsection{Limitations and Options for Follow-Up QoL Research}

This study focuses on one suburban study region and does not allow for comparisons between different study regions (e.g., of different spatial scope). Future research could explicitly address the specific role of spatial characteristics by including settlements of different scales (e.g., a small village, a medium-sized town and a large agglomeration). Such studies might further clarify the role of spatial extent and its influence on scale discrepancy theory with regard to residents' evaluations. This study built on data from one measurement point in time. Hence, dynamic aspects of urban QoL are not included. Marans and Stimson (2011) claimed the necessity of including urban change in models of urban QoL. Applying longitudinal study designs may integrate these aspects, although they often are resource intense.

This study used GIS techniques to link objective characteristics and subjective evaluations by their location in space. The use of GIS in this study was limited to the procedures of geocoding, cost-distance analysis and the spatial joining of household locations with further objective data on the urban environment. Future research on QoL could use spatial analysis in GIS, which may shed further light on the role of spatial scope in the relationships among objective and subjective predictors. For example, geographically weighted regression techniques could help analyze the local variation of estimated regression coefficients over space (Fotheringham et al. 2003). Crespo and Grêt-Regamey (2013) recently demonstrated the benefits of using local regression analysis in urban planning by analyzing the spatial variability of local parameter estimates. Evaluating the existence of clusters in the spatial arrangement of urban QoL using indices for spatial autocorrelation (e.g., Moran's I, Geary's C) could further help to understand the spatial variation in urban QoL itself. Nevertheless, in this study the test of spatial autocorrelation of the urban QoL measures did not find significant clustering (results not reported here).

The QoL indicators used in this study may be influenced by additional variables. For example, the perceived feeling of safety in a public space is apparently affected by other 
variables. There is evidence that personal exposure (i.e., victimization and explicit observation) to safety threats in public spaces affects personal feelings of safety, as do local media reports on the topic. QoL models by Jeffres and Dobos (1995) found that residents' assessment of community quality was highly dependent on the information communicated through the local media, interpersonal communication, and personal observations. Future studies on safety in public spaces should consider these influences, such as by including control variables for individual experiences with threats to safety.

Structural equation modeling was chosen as appropriate to studying the effects of mediation. Several scholars have claimed that SEM supports the interpretation of causal interrelations among variables. However, SEM builds on covariances among variables, and it is apparent that these correlational data shed only limited light on causality. Despite thorough theoretical embedding, caution should be used in making inferences of causal relations among the tested variables. Future research on urban QoL is needed, particularly in the form of controlled experimental studies. For example, choice experiments using conjoint analysis could present decomposed alternatives of urban neighborhood conditions in order to elicit the preferences of residents, as suggested by Hagerty et al. (2001). It should also be considered that the path models estimated in this study were assumed to have linear relationships between the latent variables. Considering non-linear interrelations may help in finding more coherent linkages between objective and subjective measures.

Finally, this study used a reductionist, bottom-up model to explain the influences on urban QoL. Characteristics of individuals, such as personality traits and lifestyle, were not included. Integrating such moderating factors in future research could explain further causes of weak relationships between objective urban conditions and their subjective evaluation, as suggested in top-down theories (Lance et al. 1995). A stratified analysis of individual characteristics or lifestyle habits would also allow the derivation of implications for urban policy makers who have to cope with trade-offs between investments in public spaces for different preference groups (e.g., an indoor pool vs. a kindergarten vs. public transport facilities).

Despite the identified limitations, the findings of the present study yielded new insights into the mediating effects between the predictors of urban QoL and thus have implications for supporting policy making.

\subsection{Implications for Urban Management}

An obvious, however important implication of this study is that urban policy makers should include the dimensions safety in public space and access to services and facilities in monitoring and evaluating the urban QoL. The two variables were confirmed as evident predictors of QoL. A second implication arises from the conclusion that spatial scope matters in relating objective and subjective indicators of QoL. For urban planning purposes, this means that the spatial stratification of objective and subjective QoL indicators offers an added value and should be applied. This could be implemented with the help of communal and regional GIS applications, already in use by many communities. Displaying and analyzing variations in the indicators between spatial units (e.g., neighborhoods, city districts) could highlight relative differences and potentials for interventions in certain areas.

This study found weak links between objective safety and the subjective evaluations of safety but stronger significant relations between objective and perceived measures for 
access. In monitoring urban QoL these findings imply a necessary differentiation among domains. The subjective evaluations of access and safety in public spaces were found to be significantly related to the subjective satisfaction measure for urban QoL. This finding indicated that subjective measures are appropriate in identifying the importance of different indicators to explain satisfaction with urban living. For example, urban planners and policy makers interested in a representative public opinion about the perception of urban quality (e.g., their satisfaction in using urban spaces) should analyze residents' evaluations of these QoL aspects, based on responses to survey scales. However, if the goal and implications are expected to provide guidance for interventions in the objective environment, then the use of subjective measures may not be appropriate because of their inconsistent pattern of correlations. Thus, in the case of evaluations of objective characteristics, weighted objective indicators might be preferable. Frameworks such as the four QoL states presented by Zapf (1984) may then help combining both, the results from objective measures and their subjective evaluations to reflect both dimensions when informing urban management. This may support urban policy makers, for instance, when choosing target areas and target groups for local social policies in cities.

Finally, another implication of this study is that its findings could support processes of participatory planning, which currently often lack appropriate representations of residential knowledge. Many processes of participatory urban planning still build on the engagement of only a few active residents (Burby 2003). Complementing their arguments with the representative measurement of perceived QoL attributes, combined with objective measures of the urban environment, would be a valid source of citizen inclusion.

In conclusion, this study contributed to the understanding of the interplay of important indicators of urban QoL. The study further specified research designs used in the scant previous research (e.g., McCrea et al. 2006) by testing safety in public spaces and urban access. The findings of the present study partly replicated and confirmed previous findings, while its new findings shed light on the relevance of spatial scale in relating objective characteristics and subjectively perceived measures of urban life. There is growing agreement in the scientific literature that objective and subjective predictors are necessary in the study of the QoL of places. Similarly, policy making with the purpose of enhancing QoL should also consider both dimensions (Cummins 2000; Liao 2009). The scientific debate about integrated measurement models of QoL has only recently spurred renewed interest (Costanza et al. 2007) and thus remains a subject of further research.

Acknowledgements The research presented in this article was carried out within the project "Sustainable Urban Patterns", funded by the Swiss National Science Foundation's National Research Program (NRP 65) "New Urban Quality" (http://www.nfp65.ch), Research Grant: 406540-130578. We acknowledge the valuable input given by Quang Bao Le (ETH Zurich, NSSI) into earlier versions of this work.

\section{Appendix}

See Table 4. 


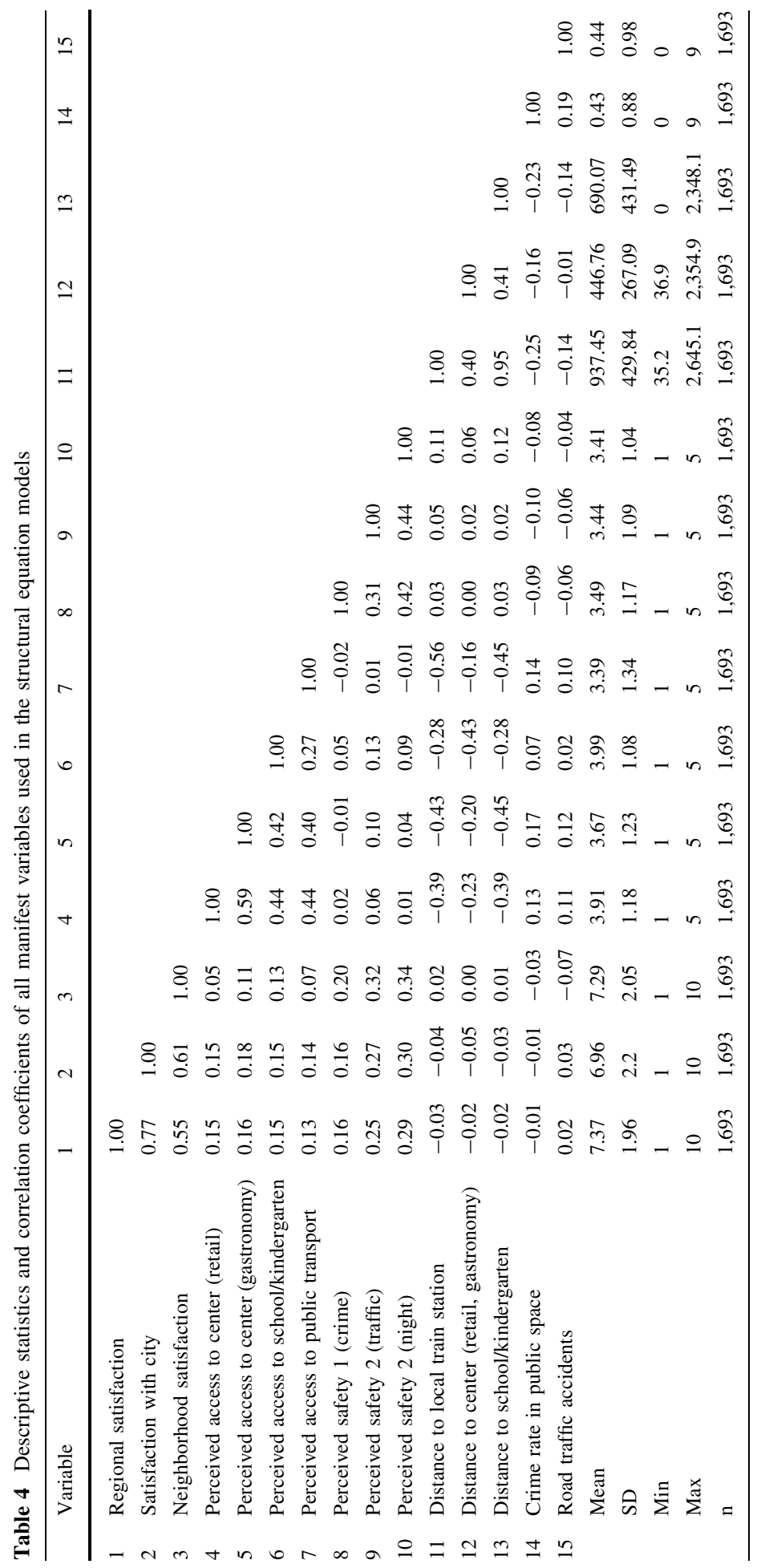




\section{References}

Acock, A. C. (2005). Working with missing values. Journal of Marriage and Family, 67(4), 1012-1028. doi:10.1111/j.1741-3737.2005.00191.x.

Adriaensen, F., Chardon, J. P., De Blust, G., Swinnen, E., Villalba, S., Gulinck, H., et al. (2003). The application of 'least-cost' modelling as a functional landscape model. Landscape and Urban Planning, 64(4), 233-247. doi:10.1016/S0169-2046(02)00242-6.

Angur, M. G., Widgery, R., \& Angur, S. G. (2004). Congruence among objective and subjective Quality-ofLife (QOL) indicators. Alliance Journal of Business Research, no Volume(issue) provided, 47-54.

Arbuckle, J. L. (2011). IBM SPSS Amos 20.0 user's guide. Chicago, IL: Amos Development Corporation.

Archibugi, F. (2001). City effect and urban overload as program indicators of the regional policy. Social Indicators Research, 54(2), 209-230. doi:10.1023/a:1011017200876.

Ballas, D. (2013). What makes a 'happy city'? Cities, 32(Supplement 1), S39-S50. doi:10.1016/j.cities. 2013.04.009.

Baron, R. M., \& Kenny, D. A. (1986). The moderator-mediator variable distinction in social psychological research: Conceptual, strategic, and statistical considerations. Journal of Personality and Social Psychology, 51(6), 1173-1182. doi:10.1037/0022-3514.51.6.1173.

Batty, M. (2013). A theory of city size. Science, 340(6139), 1418-1419. doi:10.1126/science.1239870.

Bettencourt, L. M. A., Lobo, J., Helbing, D., Kühnert, C., \& West, G. B. (2007). Growth, innovation, scaling, and the pace of life in cities. Proceedings of the National Academy of Sciences, 104(17), 7301-7306. doi:10.1073/pnas.0610172104.

Burby, R. J. (2003). Making plans that matter: Citizen involvement and government action. Journal of the American Planning Association, 69(1), 33-49. doi:10.1080/01944360308976292.

Byrne, B. M. (2010). Structural equation modeling with AMOS: Basic concepts, applications, and programming. London: Routledge.

Campbell, A., Converse, P., \& Rodgers, W. (1976). The quality of American life: Perceptions, evaluations and satisfactions. New York: Russell Sage Foundation.

Cicerchia, A. (1999). Measures of optimal centrality: Indicators of city effect and urban overloading. Social Indicators Research, 46(3), 273-299. doi:10.1023/a:1006808506878.

Costanza, R., Fisher, B., Ali, S., Beer, C., Bond, L., Boumans, R., et al. (2007). Quality of life: An approach integrating opportunities, human needs, and subjective well-being. Ecological Economics, 61(2-3), 267-276. doi:10.1016/j.ecolecon.2006.02.023.

Coulton, C., Korbin, J., Chan, T., \& Su, M. (2001). Mapping residents' perceptions of neighborhood boundaries: A methodological note. American Journal of Community Psychology, 29(2), 371-383. doi:10.1023/a:1010303419034.

Crespo, R., \& Grêt-Regamey, A. (2013). Local hedonic house-price modelling for urban planners: Advantages of using local regression techniques. Environment and Planning B: Planning and Design, 40(4), 664-682.

Cummins, R. A. (1996). The domains of life satisfaction: An attempt to order chaos. Social Indicators Research, 38(3), 303-328. doi:10.1007/bf00292050.

Cummins, R. A. (2000). Objective and subjective quality of life: An interactive model. Social Indicators Research, 52(1), 55-72. doi:10.1023/a:1007027822521.

Cummins, R. A. (2005). Moving from the quality of life concept to a theory. Journal of Intellectual Disability Research, 49(10), 699-706. doi:10.1111/j.1365-2788.2005.00738.x.

Davis, E. E., \& Fine-Davis, M. (1991). Social indicators of living conditions in Ireland with European comparisons. Social Indicators Research, 25(2-4), 103-365. doi:10.1007/bf00286160.

Diener, E. (2006). Guidelines for national indicators of subjective well-being and ill-being. Applied Research in Quality of Life, 1(2), 151-157. doi:10.1007/s11482-006-9007-x.

Evans, S., \& Huxley, P. (2002). Studies of quality of life in the general population. International Review of Psychiatry, 14(3), 203-211. doi:10.1080/09540260220145028.

Fotheringham, A. S., Brunsdon, C., \& Charlton, M. (2003). Geographically weighted regression: The analysis of spatially varying relationships. Chichester: Wiley.

Giles-Corti, B., \& Donovan, R. J. (2002). The relative influence of individual, social and physical environment determinants of physical activity. Social Science \& Medicine, 54(12), 1793-1812. doi:10. 1016/S0277-9536(01)00150-2.

Grudin, J., \& Pruitt, J. (2002). Personas, participatory design and product development: An infrastructure for engagement. In Participatory design conference, proceedings of the PDC computer professionals for social responsibility (pp. 144-161). 
Hagerty, M., Cummins, R., Ferriss, A., Land, K., Michalos, A., Peterson, M., et al. (2001). Quality of life indexes for national policy: Review and agenda for research. Social Indicators Research, 55(1), 1-96. doi:10.1023/a:1010811312332.

Hu, L. T., \& Bentler, P. M. (1999). Cutoff criteria for fit indexes in covariance structure analysis: Conventional criteria versus new alternatives. Structural Equation Modeling: A Multidisciplinary Journal, 6(1), 1-55. doi:10.1080/10705519909540118.

Jeffres, L. W., \& Dobos, J. (1995). Communication and perceptions of quality of life. In M. J. Sirgy, \& A. C. Samli (Eds.), New dimensions of marketing/quality-of-life research (pp. 227-252). Westport, CT: Quorum Books.

Kitchen, P., \& Williams, A. (2010). Quality of life and perceptions of crime in Saskatoon, Canada. Social Indicators Research, 95(1), 33-61. doi:10.1007/s11205-009-9449-2.

Lance, C., Mallard, A., \& Michalos, A. (1995). Tests of the causal directions of global-Life facet satisfaction relationships. Social Indicators Research, 34(1), 69-92. doi:10.1007/bf01078968.

Lee, T., \& Marans, R. W. (1980). Objective and subjective indicators: Effects of scale discordance on interrelationships. Social Indicators Research, 8(1), 47-64.

Liao, P. S. (2009). Parallels between objective indicators and subjective perceptions of quality of life: A study of metropolitan and county areas in Taiwan. Social Indicators Research, 91(1), 99-114. doi:10. 1007/s11205-008-9327-3.

Loukaitou-Sideris, A. (2006). Is it safe to walk? Neighborhood safety and security considerations and their effects on walking. Journal of Planning Literature, 20(3), 219-232. doi:10.1177/0885412205282770.

Loukaitou-Sideris, A., Liggett, R., Iseki, H., \& Thurlow, W. (2001). Measuring the effects of built environment on bus stop crime. Environment and Planning B: Planning and Design, 28(2), 255-280.

Lu, M. (1999). Determinants of residential satisfaction: Ordered logit vs. regression models. Growth and Change, 30(2), 264-287. doi:10.1111/0017-4815.00113.

Marans, R. W., \& Stimson, R. J. (2011). An overview of quality of urban life. In R. W. Marans, \& R. J. Stimson (Eds.), Investigating quality of urban life. Theory, methods, and empirical research (Vol. 45, pp. 1-29, Social Indicators Research Series). Dordrecht, Heidelberg: Springer.

McCrea, R., Shyy, T.-K., \& Stimson, R. (2006). What is the strength of the link between objective and subjective indicators of urban quality of life? Applied Research in Quality of Life, 1(1), 79-96. doi:10. 1007/s11482-006-9002-2.

McCrea, R., Stimson, R., \& Marans, R. (2011a). The evolution of integrative approaches to the analysis of quality of urban life. In R. W. Marans, \& R. J. Stimson (Eds.), Investigating quality of urban life (Vol. 45, pp. 77-104, Social Indicators Research Series). Netherlands: Springer.

McCrea, R., Stimson, R., \& Marans, R. (2011b). Subjective measurement of quality of life using primary data collection and the analysis of survey data. In R. W. Marans \& R. J. Stimson (Eds.), Investigating quality of urban life (Vol. 45, pp. 55-75, Social Indicators Research Series). Netherlands: Springer.

Michalos, A., \& Zumbo, B. (2000). Criminal victimization and the quality of life. Social Indicators Research, 50(3), 245-295. doi:10.1023/a:1006930019814.

Noll, H.-H. (2002). Social indicators and quality of life research: Background, achievements and current trends. In N. Genov (Ed.), Advances in sociological knowledge over half a century. Paris: International Social Science Council.

Oswald, A. J., \& Wu, S. (2010). Objective confirmation of subjective measures of human well-being: Evidence from the USA. Science, 327(5965), 576-579. doi:10.1126/science.1180606.

Rogerson, R. J., Findlay, A. M., Morris, A. S., \& Coombes, M. G. (1989). Indicators of quality of life: Some methodological issues. Environment and Planning A, 21(12), 1655-1666.

Schafer, J. L., \& Graham, J. W. (2002). Missing data: Our view of the state of the art. Psychological Methods, 7(2), 147-177. doi:10.1037/1082-989X.7.2.147.

Schumacher, M., Koch, M., \& Ruegg, J. (2004). The Zürich Limmattal. Steps of a servant valley towards emancipation. In G. Dubois-Taine (Ed.), From Helsinki to Nicosia, PUCA und COST C10. Paris: METL/PUCA.

Sirgy, M. J. (2012). Residential well-being. In M. J. Sirgy (Ed.), The psychology of quality of life: Hedonic Well-being, Life Satisfaction, and Eudaimonia (Vol. 50, pp. 303-324, Social Indicators Research Series). Netherlands: Springer.

Sirgy, M. J., \& Cornwell, T. (2002). How neighborhood features affect quality of life. Social Indicators Research, 59(1), 79-114. doi:10.1023/a:1016021108513.

Sirgy, M. J., Gao, T., \& Young, R. F. (2008). How does residents' satisfaction with community services influence quality of life (QOL) outcomes? Applied Research in Quality of Life, 3(2), 81-105. doi:10. 1007/s11482-008-9048-4.

Statistical Office Canton Zurich. (2013). Cantonal and communal statistics. http://www.statistik.zh.ch. Accessed November 13, 2013. 
Steiger, J. H. (2007). Understanding the limitations of global fit assessment in structural equation modeling. Personality and Individual Differences, 42(5), 893-898.

Swiss Federal Statistical Office (BfS). (2013). Federal population statistics for Switzerland. http://www.bfs. admin.ch/. Accessed November 13, 2013.

Talen, E. (2002). Pedestrian access as a measure of urban quality. Planning Practice and Research, 17(3), 257-278.

WHO, \& UN Habitat. (2010). Hidden cities: Unmasking and overcoming health inequities in urban settings. Kobe/Nairobi: WHO.

Zapf, W. (1984). Individuelle Wohlfahrt: Lebensbedingungen und wahrgenommene Lebensqualität. In W. Glatzer \& W. Zapf (Eds.), Lebensqualität in der Bundesrepublik Objektive Lebensbedingungen und subjektives Wohlbefinden (pp. 13-26). Frankfurt: Campus.

Zenker, S., Petersen, S., \& Aholt, A. (2013). The Citizen Satisfaction Index (CSI): Evidence for a four basic factor model in a German sample. Cities, 31, 156-164. doi:10.1016/j.cities.2012.02.006.

Zürcher Planungsgruppe Limmattal (ZPL) (2012). Entwicklung der Region 1985-2011. Facts and figures ZPL. Schlieren: Sennhauser, Werner \& Rauch AG. http://www.zpl.ch/FactsundFigures/121015_ Facts\%20und\%20Figures\%20ZPL_neu.pdf. Accessed 13 Nov 2013. 